\title{
CONSTRUÇÃO DE SENTIDOS SOBRE O CONCEITO SOCIEDADE EM TEXTOS DA INTERNET: METÁFORAS SITUADAS, FRAMES E ARGUMENTAÇÃO
}

\section{MEANING CONSTRUCTION ABOUT THE CONCEPT SOCIETY IN TEXTS FROM INTERNET: SITUATED METAPHORS, FRAMES AND ARGUMENTATION}

\author{
Ilana Souto de Medeiros (UnP) ${ }^{1}$ \\ Ada Lima Ferreira de Sousa $(\mathrm{UFRN})^{2}$
}

\section{RESUMO}

Buscamos demonstrar, neste artigo, a maneira pela qual mecanismos cognitivos se articulam no processo de construção de sentidos sobre o conceito SOCIEDADE em textos que circulam na internet. Para tanto, a título de estudo preliminar, identificamos, a partir de três excertos textuais, as metáforas situadas subjacentes aos enunciados, assim como os frames por elas articulados. Evidenciamos, por meio da análise, a conceptualização, nos excertos escolhidos, de SOCIEDADE como ORGANISMO, e reforçamos que o entrelace entre metáforas e frames é iminentemente argumentativo, pois, por meio desse recurso, teses específicas são nitidamente apresentadas e defendidas. Com isso, chamamos a atenção para o fato de que metáforas e frames, além de recursos cognitivos, são ferramentas discursivas que evidenciam visões de mundo específicas.

PALAVRAS-CHAVE: Construção de sentidos, Argumentação, Metáforas situadas, Frames.

\begin{abstract}
This article aims to demonstrate the way in which cognitive mechanisms articulate in the process of meaning construction about the concept SOCIETY in internet texts. Therefore, as a preliminary study, we identify, based on three textual excerpts, the metaphors underlying the statements, as well as the frames they articulate. Through the analysis, we highlight the conceptualization of SOCIETY as ORGANISM, in the chosen excerpts, and reinforce that the link between metaphors and frames is imminently argumentative, once specific theses are clearly presented and defended through this feature. Thus, we draw attention to the fact that metaphors and frames, in addition to cognitive resources, are discursive tools that put in evidence specific worldviews.
\end{abstract}

KEYWORDS: Meaning construction, Argumentation, Situated metaphors, Frames.

\section{INTRODUÇÃO}

A metáfora, vista na Antiguidade Clássica como tropo linguístico, há muito é considerada um fenômeno do pensamento, que revela importantes aspectos das nossas práticas linguísticas cotidianas e da maneira como percebemos o mundo. Tal entendimento se apresenta, por exemplo, no campo da Linguística Cognitiva de base corporificada, que considera que "a linguagem não deve ser concebida, em si mesma, como geradora e portadora de sentidos, uma vez que muitos de nossos processos linguísticos, inextricavelmente relacionados ao resto de nosso sistema físico e cognitivo, são figurativamente estruturados" (SOUSA; COSTA, 2016). Esse entendimento é inaugurado em Lakoff e Johnson (1980), que descrevem a metáfora como

\footnotetext{
${ }^{1}$ Doutora em Estudos da Linguagem pela Universidade Federal do Rio Grande do Norte (UFRN) e professora na Universidade Potiguar (UnP). E-mail: ilanasouto@hotmail.com.

2 Doutora em Estudos da Linguagem pela UFRN e professora adjunta na mesma instituição. E-mail: adalima@gmail.com.
} 
um processo caracterizado por um mapeamento entre domínios componentes do nosso sistema conceptual.

Cabe ressaltar que, uma vez que se constituem como processos cognitivos resultantes da nossa experiência no mundo, aos quais temos acesso por meio da linguagem, as metáforas "potencialmente ocorrem em qualquer tipo de comunicação e, sendo assim, guiam também objetivos particulares de ação" (SCHRÖDER, 2009, p. 106). Tal entendimento é compartilhado por Kövecses (2005), que destaca o fato de as metáforas, enquanto mediadoras entre cognição e linguagem - e entre entre indivíduo e sociedade -, exercerem papel central na criação da cultura.

Partindo dessa perspectiva, compreendemos que as mais diversas manifestações discursivas podem ser tomadas como lócus para a investigação de metáforas a fim de melhor entender como indivíduos, em interação com a sociedade, constroem os mais diversos conceitos e revelam tal construção por meio da linguagem. Nesse sentido, iniciamos um estudo sobre como o conceito de SOCIEDADE ${ }^{3}$ é estruturado, metaforicamente, em textos que circulam na internet. Com vistas a tal objetivo, neste artigo, subsidiado teórica e metodologicamente pelos princípios da Linguística Cognitiva de base corporificada, pretendemos evidenciar a articulação metafórica de frames em excertos textuais que abordam o referido conceito, de modo a ratificar como, por meio de metáforas situadas, é possível construir, discursivamente, determinadas visões de mundo.

Para fundamentar nossa análise, adotamos a noção de frame proposta por Fillmore e Baker (2009), que compreendem frames como mecanismos acionados e indexados por construções linguísticas, e o conceito apresentado por Duque (2015), segundo o qual frames são circuitos neurais acionados pela linguagem.

Além dos frames, elegemos, enquanto categoria analítica, a metáfora, compreendida, neste artigo, em linhas gerais, como um mapeamento entre frames distintos, de modo a conceptualizar um deles em termos de aspectos do outro. Nesse sentido, apresentamos os princípios que regem a Teoria da Metáfora Conceptual (LAKOFF; JOHNSON, 1980) e, em seguida, discorremos sobre as metáforas situadas (VEREZA, 2013, 2016).

Nosso corpus é composto por três excertos de textos extraídos da internet que abordam o conceito SOCIEDADE. Para constituí-lo, utilizamos a ferramenta de busca Google e, após digitarmos a palavra "sociedade" na aba "notícias", selecionamos, aleatoriamente, três linkes que nos deram acesso a diferentes textos. Cabe ressaltar que, uma vez que se trata de um estudo preliminar, não pretendemos, aqui, estabelecer generalizações, mas, como já posto, apontar como é possível, por meio de construções metafóricas, defender visões de mundo acerca do referido conceito.

No que concerne à sistematização da análise dos dados, os excertos apresentados foram identificados por algarismos arábicos e seguidos por notas de rodapé, nas quais fornecemos os links de acesso aos textos completos. Em cada excerto, destacamos, em itálico, os itens e/ou expressões linguísticas que nos auxiliaram a identificar a construção de metáforas situadas e os frames por ela acionados. Por fim, ilustramos, por meio de figuras, as redes conceptuais tecidas por esses mecanismos e discorremos sobre os sentidos que, a partir delas, podem ser depreendidos.

\section{Frames}

A noção de frame, discutida em diversas áreas do conhecimento, tais como a Psicologia, a Antropologia, a Inteligência Artificial, entre outras, possui distinções nos diversos campos em que é utilizada. De modo geral, é evocada em referência aos aspectos inferenciais envolvidos na compreensão da linguagem (FILLMORE, 1982). Nesse sentido, a busca por esses aspectos é, inclusive, anterior a termos tais como frames, scripts e cenários, utilizados, nos anos 1970, por vários pesquisadores da área de Inteligência Artificial que pretendiam dar conta das

\footnotetext{
${ }^{3}$ Em conformidade com a perspectiva teórica adotada neste artigo, utilizamos a notação de Duque (2015), em que conceitos/frames são grafados em versalete.
} 
representações do conhecimento de mundo e do papel delas no processamento discursivo. No campo da Psicologia, por exemplo, Bartlett (1932, apud VAN DIJK, 2004), ao desenvolver estudos sobre a memória com o auxílio de materiais discursivos como fotos e pequenas histórias, empregou o termo schemata para se referir às estruturas mentais envolvidas na compreensão do discurso.

A introdução do conceito de frame na área das ciências humanas e sociais, segundo Gonçalves (2005), é atribuída ao antropólogo e epistemólogo da comunicação anglo-americano Gregory Bateson. No artigo $A$ theory of play and phantasy, publicado pela primeira vez em 1954, o pesquisador apresenta o frame como um conceito psicológico relacionado ao contexto, sendo este entendido como a situação partilhada pelos interlocutores. É essa situação comunicativa, segundo Bateson, que determina a organização da estrutura de sentidos das mensagens e das ações compartilhadas pelas pessoas num determinado contexto. Quando, por exemplo, após relatar uma situação dramática a um amigo, dizemos "é mentira", estabelecemos um frame que faz o interlocutor reconfigurar sua percepção das mensagens apresentadas até então e entendê-las como falsas.

A ideia de os frames estarem relacionados ao modo como organizamos nossa percepção do mundo também é utilizada por Goffman (1974), que propõe a análise do arranjo das experiências individuais do homem enquanto um ser envolvido em interações sociais. Segundo o sociólogo, definimos situações em função de princípios de organização que governam eventos sociais bem como nosso envolvimento subjetivo neles. Portanto, para esse autor, os frames também são entendidos como elementos estruturadores das nossas experiências cotidianas, os quais definem o modo como compreendemos situações e interagimos com nossos pares.

O conceito de frame também aparece em trabalhos desenvolvidos no campo da Inteligência Artificial nos anos 1970. Nesse período, de acordo com Van Dijk (2004, p.12),

[...] a compreensão da linguagem simulada por computador requeria o desenvolvimento de programas para o processamento automático de textos. Por exemplo, a modelagem do conhecimento de mundo necessário à compreensão de estórias era crucial para esse tipo de pesquisa.

Essa breve recuperação do conceito de frame indica que há, em diversas áreas, um aspecto convergente no que tange a essa ação: a de que frames são estruturas mentais que, de certo modo, orientam nosso comportamento.

$\mathrm{Na}$ Linguística, mais especificamente, a noção de frames foi sistematizada por Charles Fillmore. Em um de seus primeiros trabalhos, "Frame Semantics and the Nature of Language", de 1976, o linguista sinaliza a importância de se considerar, na caracterização de um sistema linguístico, a descrição de frames cognitivos e interacionais, em termos dos quais o usuário da língua "[...]interpreta seu ambiente, formula suas próprias mensagens, compreende as mensagens dos outros e acumula ou cria um modelo interno de seu mundo" (FILLMORE, 1976, p. 23 [tradução nossa] $]^{4}$ ). Nesse sentido, frames são definidos pelo autor como uma espécie de inventário de esquemas que as pessoas possuem na memória, que as auxilia a estruturar, classificar e interpretar experiências. Ele acrescenta, também, que os significados das palavras são dependentes de experiências contextualizadas.

Em estudos posteriores, especificamente no que foi realizado em parceria com Collin Baker, Fillmore desenvolveu a Semântica de Frames, sintetizada como o estudo da maneira como itens lexicais evocam ou ativam frames e como estes, sendo ativados, são passíveis de integração em prol da compreensão de passagens que contêm tais formas linguísticas (FILLMORE; BAKER, 2009, p. 317). Dessa forma, frames são compreendidos como mecanismos cognitivos, enquanto as construções linguísticas funcionam como guias que os ativam.

\footnotetext{
4 “[...] interprets his environment, formulates his own messages, understands the messages of others, and accumulates or creates an internal model of his world".
}

Revista do GELNE, Natal/RN, Vol. 23 - Número 1: p. 157-168. Fevereiro. 2021 
Neste trabalho, também utilizamos a noção proposta por Duque (2015; 2017), segundo a qual frames são vistos como circuitos neurais ativados e acionados pela linguagem, por meio dos quais organizamos pensamentos, ideias e visões de mundo. Adotamos, também, a metodologia para análise de frames aplicada ao discurso, que permite observar, com o auxílio de indexadores linguísticos, as dimensões que constituem um frame: cognitiva e interacional (DUQUE, 2015). Segundo o autor, a dimensão cognitiva abrange frames conceptuais básicos ${ }^{5}$, descritores de evento, roteiro, esquemas imagéticos (esquemas-I), sociais, de domínio específico e culturais. A dimensão interacional, por sua vez, é constituída por frames interacionais. Cumpre destacar que a divisão entre essas duas dimensões, como destaca o linguista, é feita por questões de ordem didática, uma vez que elementos cognitivos perpassam a dimensão interacional e vice-versa.

Sob essa perspectiva conceptual, Duque (2015) sugere que frames podem ser acionados por meio de itens e/ou expressões lexicais. No discurso, esse tipo de frame é linguisticamente indexado por substantivos e expressões nominais. Tomemos como exemplo o frame CASA. Nele estão contidas todas as informações e as experiências que cada sujeito possui com relação a esse tipo de moradia, desde elementos básicos, como os materiais necessários à sua construção (tijolos, cimento, telhas, etc.), até elementos mais complexos, como questões culturais (diferentemente do Brasil, em alguns países, por exemplo, não é comum o uso de chuveiros elétricos nos banheiros da casa).

Em um enunciado como "[...] A casa possui três quartos, dois banheiros e tem uma atmosfera leve e arejada graças à grande quantidade de janelas [...]"' (grifos nossos), notamos que os itens linguísticos em destaque ativam o frame conceptual básico CASA, como ilustra a figura 1.

Figura 1: Alguns dos itens constituintes do frame CASA.

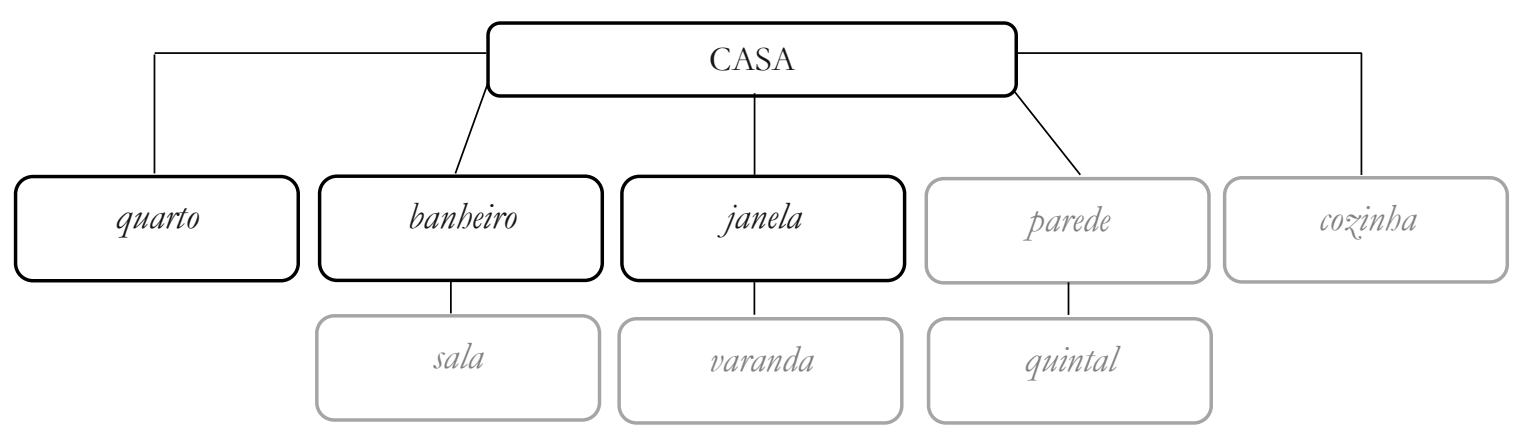

Fonte: elaborada pelas autoras.

Verificamos, na figura 1, que os itens ressaltados no enunciado (“quartos", "banheiros" e "janelas") ativam o frame CASA. Esses mesmos itens, no entanto, acionam, também, partes específicas desse frame, ou seja, focalizam os constituintes quarto, banheiro e janela, ilustrados na cor preta. Embora apenas essas partes estejam em evidência, já que somente elas foram linguisticamente indexadas, várias outras são ativadas ao mesmo tempo, como é o caso de parede, cozinha, sala, varanda e quintal, destacadas em cinza. Isso significa, em outras palavras, que os constituintes não acionados por itens linguísticos permanecem em stand by e, a qualquer momento, podem ser realçados no discurso.

Ainda de acordo com a figura 1, é possível observar que um frame, como CASA, possui uma estrutura reticulada composta por constituintes que, por sua vez, podem assumir o papel de

\footnotetext{
5 Como o principal objetivo deste artigo é o de evidenciar, por meio de pistas linguísticas (sobretudo itens e/ou expressões lexicais), como o conceito SOCIEDADE é construído no discurso, daremos ênfase apenas a esse tipo de frame.

6 Disponível em: https://revistacasaejardim.globo.com/Casa-e-Jardim/Arquitetura/noticia/2018/04/ casa-em-formato-de-piramide-esta-venda-em-malibu.html. Acesso em: 25 mar. 2019.
} 
frames. Nesse sentido, banheiro, no enunciado supracitado, é constituinte do frame CASA, mas, em um enunciado como "[...] O banheiro é grande e possui uma banheira. O boxe é um pouco pequeno, mas não prejudica. O chuveiro é bom e tem água quente" ${ }^{\text {"7 }}$ (grifos nossos), ele se torna um frame, que, por seu turno, possui outros constituintes: banheira, boxe e chuveiro, como mostram os itens em destaque, entre outros.

\section{Metáforas situadas}

Para subsidiar a análise apresentada neste artigo, utilizamos a noção de metáfora situada, proposta por Vereza (2013, 2016). Antes de nos aprofundarmos nesse conceito, é necessário discutirmos brevemente alguns dos princípios básicos da Teoria da Metáfora Conceptual (TMC), desenvolvida por Lakoff e Johnson (1980).

A TMC, que surge no início da década de 1980, rompe com um pensamento cristalizado durante séculos, segundo o qual as metáforas, inseridas exclusivamente na esfera linguística, são concebidas como ornamento, ou seja, como um recurso estilístico cuja única finalidade seria a de embelezar o discurso.

Lakoff relembra que a concretização dessa ruptura de paradigma inicia-se com as ideias propostas por Michael Reddy, desenvolvidas no artigo The Conduit Metaphor, publicado em 1979. Nesse estudo, Reddy propôs, por meio de um único caso significativo, que

O lócus da metáfora é o pensamento, não a linguagem, que a metáfora é uma grande e indispensável parte do nosso modo convencional de conceptualizar o mundo, e que nosso comportamento diário reflete nossa compreensão metafórica da experiência (LAKOFF, 1992, p. 2 [tradução nossa] $^{8}$ ).

Partindo dessa nova compreensão, Lakoff e Johnson sugerem, na TMC, que as metáforas são decorrentes de um mapeamento (correspondências conceptuais) entre um domínio ${ }^{9}$ fonte, de base mais experiencial, e um domínio alvo, de natureza menos experiencial. Nesse sentido, as metáforas passam a ser vistas como um mecanismo cognitivo por meio do qual conceptualizamos, de modo inconsciente, um domínio da experiência em termos de outro.

Um exemplo clássico trazido por Lakoff (1992) é o da metáfora conceptual RELACIONAMENTO AMOROSO É UMA VIAGEM ${ }^{10}$, que pode ser linguisticamente identificada em um enunciado como, por exemplo, "nossa relação chegou a um beco sem saída". Essa metáfora, segundo o autor, apresenta um conjunto de correspondências que caracterizam um mapeamento no qual os amantes correspondem aos viajantes; o relacionamento amoroso, ao veículo; os objetivos comuns dos amantes, aos seus destinos comuns na viagem; e as dificuldades encontradas na relação, aos empecilhos que podem surgir ao longo da viagem.

Em outras palavras, observamos, nessa metáfora, a existência de uma projeção entre dois frames decorrentes da experiência humana: AMOR e VIAGEM. Nela, o frame fonte (VIAGEM) é conceptualizado no frame alvo (AMOR). Isso acontece como uma forma de tentar tornar um conceito mais distante de nossas experiências corpóreas, como o AMOR, em algo mais próximo de alguma situação já experienciada fisicamente, como VIAGEM, por exemplo.

\footnotetext{
7 Disponível em: https://www.paraviagem.com.br/vila-gale-eco-resort-em-angra-dos-reis/. Acesso em: 25 mar. 2019.

8 "Reddy showed, for a single very significant case, that the locus of metaphor is thought, not language, that metaphor is a major and indispensable part of our ordinary conventional way of conceptualizing the world, and that our everyday behavior reflects out metaphorical understanding of experience".

${ }^{9}$ A noção de domínio, utilizada pelos autores, é equivalente à noção de frame aqui defendida.

10 Metáforas conceptuais, conforme notação utilizada por Lakoff e Johnson (1980) e Duque (2015), são grafadas em versalete.
}

Revista do GELNE, Natal/RN, Vol. 23 - Número 1: p. 157-168. Fevereiro. 2021 
Se, de modo resumido, as metáforas conceptuais podem ser compreendidas como mecanismos pertencentes ao nosso sistema conceptual, e, por essa razão, são consideradas estruturas estáveis, tais quais os Modelos Cognitivos Idealizados (LAKOFF, 1987), as metáforas situadas, como sugere Vereza (2013, p. 10), são de natureza deliberada e "[...] mesmo não sendo sempre textualmente explicitadas (na forma x é y), conferem coerência e unidade cognitiva do discurso online".

Enquanto as metáforas conceptuais fazem parte de um nível estável de cognição, no qual se inserem estruturas mais estáveis, como os MCIs, os esquemas imagéticos, dentre outros, as metáforas situadas compõem o nível episódico de cognição, que é associado, mais precisamente, à linguagem em uso (VEREZA, 2016). Nesse nível, instâncias do nível estável podem ser recrutadas para licenciar estruturas episódicas, razão pela qual os dois níveis, separados apenas por questões analíticas, mantêm uma relação de simbiose.

Outra característica importante das metáforas situadas, conforme a autora, é a sua natureza potencialmente argumentativa. Em um de seus trabalhos, Vereza (2013) analisa a ocorrência dessas metáforas em memes e constata que os sentidos por elas construídos contribuem ativamente para o desenvolvimento da argumentação.

No intuito de exemplificarmos a emergência de uma metáfora situada, recorremos à ferramenta de busca Google e, ao digitarmos o termo "sociedade" (conceito selecionado para procedermos à análise), encontramos diversos casos de metáforas situadas, como o que se verifica, por exemplo, no enunciado: "Sem dúvida, ele já alinhavou, já costurou o grande entendimento para que a tão esperada e sonhada reforma política, que é a cabeça da sociedade, possa ocorrer. Ele traz a sua condição moral, a sua experiência, associada com o grande prestígio do nosso estimado Presidente Lula, e o nosso Presidente Michel Temer [...]"11 (grifos nossos).

Notamos, com o auxílio dos itens linguísticos destacados, "reforma política" e "cabeça da sociedade", a existência de uma projeção metafórica, por meio da qual um frame fonte (REFORMA POLÍTICA) se projeta em um frame alvo (CABEÇA). A metáfora que emerge dessa projeção, reforma política é cabeça ${ }^{12}$, é considerada situada por sua natureza deliberada e episódica, e, também, pelo fato de ela recrutar instâncias de um nível mais estável da cognição (uma metáfora conceptual, nesse caso).

Nesse sentido, podemos depreender que a metáfora situada reforma política é cabeça foi licenciada pela metáfora conceptual SOCIEDADE É ORGANISMO, pois, como mostra o texto, mais precisamente a expressão "cabeça da sociedade", a sociedade é compreendida como algo que tem cabeça (parte de um organismo).

Por meio da metáfora situada verificada no enunciado supracitado, observamos, também, seu teor argumentativo, o que decorre da focalização dada a determinados frames e não a outros. Dito de outro modo, o autor do texto, ao selecionar o frame CABEÇA para fazer referência à reforma política, constrói sentidos bastante específicos. Uma vez que determinadas propriedades do frame alvo (como a importância da cabeça enquanto uma das partes responsáveis pela manutenção da vida de um organismo) são compartilhadas com o frame fonte (REFORMA POLÍTICA), inferimos que, para o autor, a reforma política é de grande relevância para a sociedade. Esse argumento não seria tão evidente se, no lugar da cabeça, partes menos indispensáveis a um organismo fossem usadas como frame alvo.

$\mathrm{Na}$ seção seguinte, dedicada à análise do corpus, apresentaremos outras três ocorrências de metáforas situadas que emergem a partir do conceito SOCIEDADE. Além de identificá-las linguisticamente e de verificar se elas são ou não licenciadas por metáforas conceptuais, mostraremos que essas metáforas, quando acionam frames distintos, constroem sentidos diversos e particulares.

${ }^{11}$ Disponível em: https://www25.senado.leg.br/web/atividade/pronunciamentos/-/p/texto/378204. Acesso em 28 mar. 2019.

${ }^{12}$ Metáforas situadas são grafadas em itálico, conforme notação utilizada por Vereza (2013). 


\section{Análise e discussão dos dados}

Apresentamos, nesta seção, a análise dos três excertos de textos que selecionamos como corpus. Cumpre relembrar que, como já previsto, utilizamos a ferramenta de busca Google, especificamente a aba "notícias", para coletar, aleatoriamente, situações reais de uso da língua que abordassem o conceito SOCIEDADE. Ressaltamos, mais uma vez, que, sendo este estudo preliminar, nosso objetivo, neste momento, não é, ainda, fazer generalizações acerca das metáforas sobre SOCIEDADE, mas observar ocorrências pontuais que nos levem a tecer considerações sobre a articulação metafórica, a partir de algumas amostras textuais, de modo a verificar como se constroem certas visões de mundo acerca desse conceito. Nas três ocorrências, enumeradas por algarismos arábicos, apresentamos o trecho extraído da internet, identificamos os itens linguísticos que licenciam a construção de metáforas situadas e, por fim, discorremos sobre os argumentos nelas ancorados.

(01) "[...] 'Para mim significa muita coisa, é minha vida, o voleibol me trouxe tudo. Comecei muito cedo, trabalhei com grandes gerações do esporte, grandes duplas, seleção brasileira, campeões olímpicos, morei fora quatro anos e ver Maricá, uma cidade litorânea, dar valor a um esporte que traz tanta alegria é muito bacana. Sou treinador de vôlei de praia poder prestigiar um evento como esse com uma estrutura bacana com respeito ao atleta e às pessoas que estão aqui e trazer mais um polo esportivo que trata o esporte como um braço da sociedade', destacou"13 (grifo nosso).

Verificamos, em (01), sobretudo com o auxílio dos itens destacados, que a sociedade é compreendida em termos de um organismo, uma vez que, como se observa na passagem "[...] esporte como um braço da sociedade [...]", há uma referência a um membro específico do corpo humano: o braço. Notamos, também, que esse membro é recuperado metaforicamente pelo item lexical "esporte".

A partir da articulação que se estabelece entre esses itens, identificamos a construção da metáfora situada esporte é braço da sociedade. Por meio dela, é possível observar um mapeamento que é tecido online, a partir do qual propriedades do frame fonte BRAÇO são projetadas para o frame alvo ESPORTE. Nesse sentido, importantes funções do braço, como as que se referem à execução de tarefas específicas como a de empurrar, de sustentar, dentre outras, são compartilhadas com o esporte.

A metáfora situada esporte é braço da sociedade, verificada em (01), aciona frames específicos, cuja interação edifica uma rede conceptual rica em significados, como ilustra a figura 2:

13 Texto completo disponível em: http://maricainfo.com/2017/12/05/marica-circuito-praia-2017-comeca-comdisputas-de-volei-na-praia-da-barra.html. Acesso em: 27 fev. 2019. 
Figura 2: Rede conceptual construída pelos frames acionados com o auxílio da metáfora situada esporte é braço da sociedade.

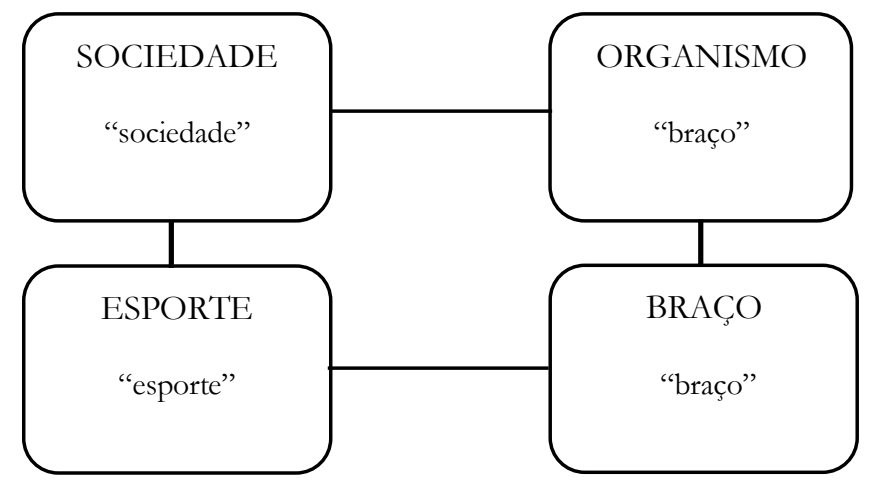

Fonte: elaborada pelas autoras.

Constatamos, a partir da figura 2, que a metáfora situada supracitada aciona quatro frames: SOCIEDADE, linguisticamente indexado pelo item "sociedade"; ORGANISMO e BRAÇO, instanciados por "braço"; e ESPORTE, recuperado pelo item lexical "esporte".

Como dissemos, as relações estabelecidas entre esses frames são de natureza metafórica, uma vez que a sociedade é compreendida em termos de um organismo e o esporte é concebido como um de seus membros: braço. Além disso, a rede conceptual expressa na figura 2 possui teor argumentativo, conforme discorremos a seguir.

O excerto apresentado em (01), orientado pela metáfora situada esporte é um braço da sociedade, enquadra o esporte como um membro que oferece, ao corpo, elementos como força e sustentação. A escolha do item lexical "braço", que, a nosso ver, não foi aleatória, evoca a tese de que o esporte é um elemento de apoio para a sociedade, mas não o elemento principal.

À semelhança do que foi observado em (01), os enunciados dispostos em (02) também nos permitem identificar, por meio de insumos linguísticos, a ocorrência de uma metáfora situada por meio da qual frames são acionados e, consequentemente, argumentos são tecidos:

(02) "[...] O Badrutt's Palace, com sua torre de telhado verde funcionando como verdadeiro marco da Via Serlas, é o coração da sociedade de St. Moritz. O King's Social House, que opera dentro dele, é o clube mais antigo da Suiça e serve jantar e coquetéis para uma clientela que gosta de esticar a refeição para dançar no lounge do subsolo [...]"14 (grifos nossos).

Nesse excerto, percebemos que o conceito SOCIEDADE também é compreendido em termos de um organismo, o que se deve, sobretudo, à utilização do item lexical "coração", verificado na passagem "[...] é o coração da sociedade [...]". Constatamos, além disso, que esse órgão é metaforicamente representado por "Badrutt's Palace" - um hotel luxuoso e histórico, localizado na cidade de St. Moritz, na Suíça ("O Badrutt's Palace [...] é o coração da sociedade de St. Moritz [...]").

Por meio dos indexadores linguísticos disponíveis em (02), especialmente os que estão destacados em negrito, identificamos a construção da metáfora situada Badrutt's Palace é coração da sociedade de St. Moritz, licenciada, por sua vez, pela metáfora conceptual SOCIEDADE É ORGANISMO. No mapeamento a ela subjacente, verificamos que propriedades do frame fonte CORAÇÃO, como "órgão vital para o organismo", são compartilhadas com o frame alvo BADRUTT’S PALACE.

Ademais, notamos que a projeção que permite a emergência da metáfora situada Badrutt's Palace é coração da sociedade de St. Moritz enquadra frames específicos que, quando se articulam, tecem

\footnotetext{
14 Texto completo disponível em: https://gauchazh.clicrbs.com.br/comportamento/viagem/ noticia/2019/02/36-horas-em-st-moritz-cjrw7xxph01zu01li85bg590d.html. Acesso em: 27 fev. 2019.
} 
uma rede conceptual, ilustrada na figura 3, por meio da qual sentidos diversos podem ser depreendidos:

Figura 3: Rede conceptual construída pelos frames acionados com o auxílio da metáfora situada Badrutt's Palace é coração da sociedade de St. Moritz.

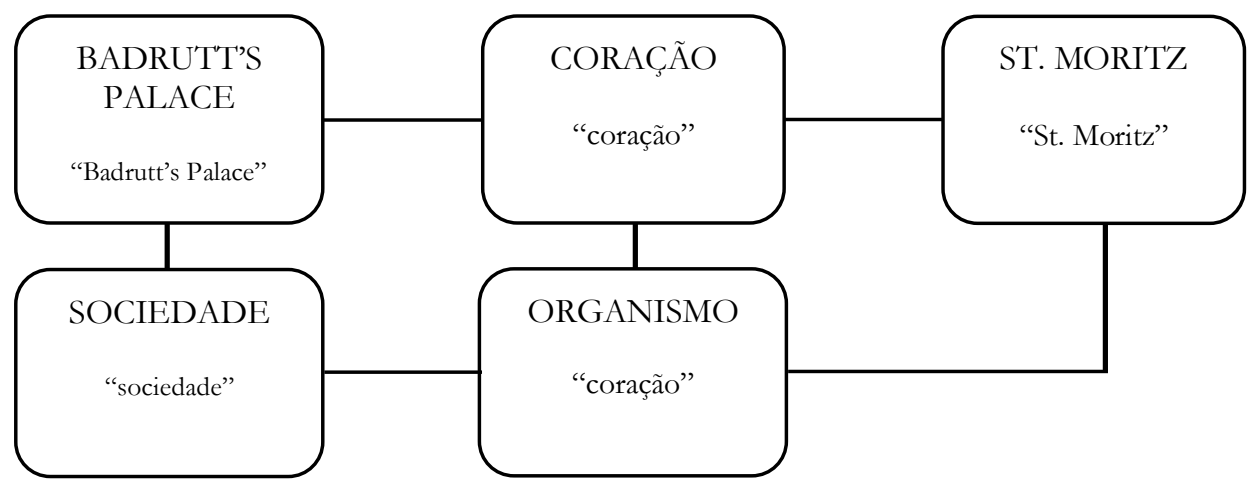

Fonte: elaborada pelas autoras.

Como mostra a figura 3, os itens linguísticos que constituem a metáfora situada Badrutt's Palace é coração da sociedade de St. Moritz. acionam cinco frames: BADRUTT'S PALACE, indexado por "Badrutt's Palace"; CORAÇÃO, instanciado pelo item lexical "coração"; ST. MORITZ, linguisticamente indexado por "St. Moritz"; SOCIEDADE, instanciado por "sociedade"; e ORGANISMO, também indexado pelo item "coração".

As relações que emergem da interação entre esses frames são metafóricas, pois, como dissemos, a sociedade é compreendida em termos de um organismo, uma parte desse organismo é focalizada (coração) e essa parte é associada a um luxuoso hotel suíço, o Badrutt's Palace. Tais relações, cumpre relembrar, licenciam a construção da metáfora situada Badrutt's Palace é coração da sociedade de St. Moritz:

Outra característica que pode ser identificada na rede conceptual expressa na figura $3 \mathrm{diz}$ respeito à sua natureza argumentativa, a partir da qual sentidos específicos podem ser inferidos. Isso é percebido graças à escolha do item lexical "coração", que faz referência a um órgão considerado central no tocante à manutenção da vida, pois uma de suas principais funções é a de bombear e distribuir o sangue oxigenado para todo o corpo.

Nesse sentido, associar o Badrutt's Palace a um coração constrói a tese de que esse hotel é considerado um elemento indispensável para a vida da cidade de St. Moritz, assim como é o coração para um organismo. Dito de outro modo, o não funcionamento do Badrutt's Palace poderia significar a morte de St. Moritz.

Percebemos, em (01), que a metáfora situada esporte é braço da sociedade, por ter sido construída a partir da focalização do frame fonte BRAÇO, apresenta a tese de que o esporte pode ser concebido como um importante elemento para a sociedade, mas não como o elemento central. Já em (02), essa noção de centralidade é evocada, pois, como vimos, a metáfora situada Badrutt's Palace é coração da sociedade de St. Moritz utiliza como frame fonte um órgão vital para a vida, o coração.

Com o intuito de verificar se, de fato, a escolha do frame fonte é importante no que se refere aos argumentos tecidos por metáforas situadas, procedemos à análise da última ocorrência que compõe o corpus constituído para este trabalho: 
(03) “[...] ÉPOCA - O ex-ministro da Justiça Márcio Thomaz Bastos disse recentemente que a imprensa já tomou partido contra os réus do mensalão. O senhor concorda?

Velloso - 'Tenho pelo doutor Márcio Thomaz Bastos a maior admiração. Ele é notável advogado e grande criminalista. Divirjo, entretanto, quando ele afirma que a imprensa já tomou partido contra os réus do mensalão. Não, a imprensa não tomou partido. A imprensa está, simplesmente, noticiando livremente. Nesse sentido, ela se põe como pulmão da sociedade. Ai deste país não fosse a imprensa livre! Quanta coisa ficaria encoberta"'15 (grifos nossos).

Assim como identificado em (01) e em (02), notamos, em (03), que os itens linguísticos disponíveis, sobretudo os destacados, permitem compreender a sociedade como um organismo, uma vez que ela possui pulmão (“[...] pulmão da sociedade [...]”). Esse órgão, conforme a passagem "[...] A imprensa está, simplesmente, noticiando livremente. Nesse sentido, ela se põe como pulmão da sociedade [...]", é metaforicamente representado pelo item lexical "imprensa".

Essas associações, SOCIEDADE/ORGANISMO e IMPRENSA/PULMÃO, nos permitem inferir que o excerto descrito em (03) é amparado pela metáfora situada imprensa é pulmão da sociedade. No mapeamento nela construído, é possível observar que características intrínsecas ao frame fonte PULMÃO, como a de órgão cuja função é oxigenar o sangue e eliminar o dióxido de carbono do corpo, são projetadas para o frame alvo IMPRENSA.

Assim como constatado nos excertos anteriores, a metáfora situada (imprensa é pulmão da sociedade, em se tratando de (03)) é responsável pelo acionamento de frames que, por sua vez, constroem, a partir de suas conexões, uma rede conceptual imersa em significados, como a ilustrada na figura 4 :

Figura 4: Rede conceptual construída pelos frames acionados com o auxílio da metáfora situada imprensa é pulmão da sociedade.

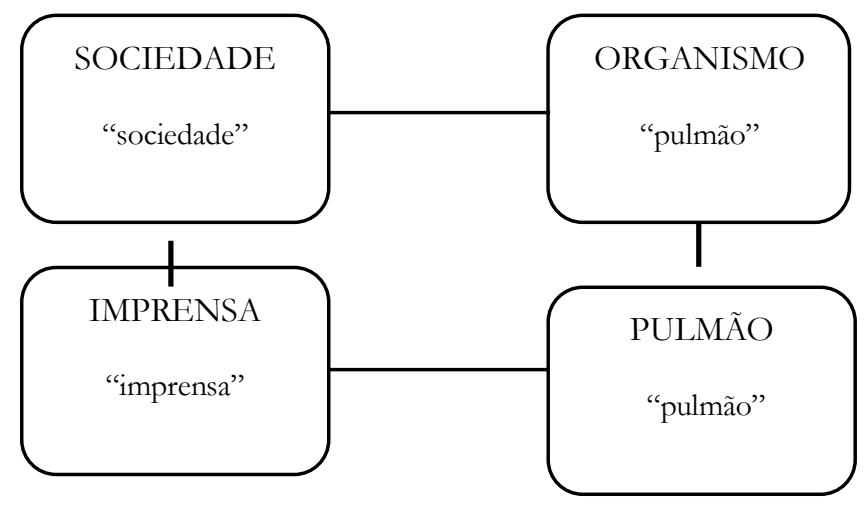

Fonte: elaborada pelas autoras.

Nessa rede, conforme a figura 4, quatro frames são acionados: SOCIEDADE, linguisticamente indexado pelo item lexical "sociedade"; ORGANISMO, instanciado por "pulmão"; IMPRENSA, indexado pelo item "imprensa"; e PULMÃO, também instanciado pelo item lexical "pulmão".

Esses frames, quando interagem, criam um elo de natureza metafórica, pois frames considerados mais distantes de nossas experiências físicas, como SOCIEDADE e IMPRENSA, são concebidos em termos de frames mais próximos de nossas experiências básicas, como ORGANISMO e PULMÃo. Essas associações, como mostramos, licenciam a construção da metáfora situada imprensa é pulmão da sociedade.

15 Texto completo em: http://revistaepoca.globo.com/tempo/noticia/2012/08/carlos-velloso-imprensa-naotomou-partido.html. Acesso em: 27 fev. 2019. 
Além do teor metafórico, a rede conceptual expressa na figura 4 apresenta um caráter potencialmente argumentativo, o que ocorre devido à escolha do item lexical "pulmão", por meio do qual o frame fonte é acionado. Desse modo, todas as propriedades desse frame são compartilhadas com o frame alvo IMPRENSA.

Nesse contexto, a tese defendida em (03) é a de que a imprensa é vista como um importante órgão social, pois, graças a ela, a sociedade respira - da mesma maneira que o pulmão garante a respiração de um organismo.

\section{CONSIDERAÇÕES FINAIS}

Com a análise preliminar apresentada neste artigo, reforçamos que as metáforas situadas podem ser consideradas poderosas ferramentas no tocante à construção de argumentos e à defesa de visões de mundo, o que as torna, além de mecanismos cognitivos, um recurso discursivo em potencial.

Isso acontece, como foi exposto, devido às escolhas lexicais feitas pelos autores dos textos, pois as propriedades dos frames fonte acionadas por determinados itens linguísticos são compartilhadas com o frame alvo, o que confere, às metáforas situadas construídas, graus de persuasão.

No primeiro excerto apresentado, verificamos que a metáfora situada esporte é braço da sociedade enquadra o esporte como um importante segmento social, mas não como algo central para a sociedade. A dimensão de centralidade seria dada, por exemplo, se o autor do texto tivesse utilizado, no lugar do item lexical "braço", para acionar o frame fonte, itens lexicais associados a órgãos considerados mais centrais para o corpo humano.

Isso foi percebido no segundo excerto, sustentado pela metáfora situada Badrutt's Palace é coração da sociedade de St. Moritz. Ao selecionar o item linguístico "coração" como indexador do frame fonte, o autor do texto validou a tese de que o hotel suíço Badrutt's Palace é, além de importante, central para a vida da cidade de St. Moritz.

De modo semelhante, a utilização do item "pulmão" (que também é considerado um dos principais órgãos do corpo humano) para instanciar o frame fonte a partir do qual propriedades são compartilhadas com o frame alvo construiu, com o auxílio da metáfora situada imprensa é o pulmão da sociedade, uma tese bastante persuasiva: a de que a imprensa é um importante elemento social, pois, graças a ela, a sociedade é capaz de respirar.

As repercussões discursivas de estratégias como as que vimos são inúmeras, pois argumentos como esses legitimam formas de pensar bastante específicas. Nesse sentido, os leitores que têm acesso a textos como os aqui apresentados podem ser levados, sem perceber, a adotar as mesmas visões de mundo defendidas pelos autores.

Embora o foco de nossa análise tenha sido o conceito SOCIEDADE, inferimos que inúmeros outros conceitos considerados mais abstratos, como ECONOMIA, GUERRA, POLÍTICA, entre outros, também sejam enquadrados por metáforas situadas que, por acionar frames específicos, constroem argumentos por meio dos quais visões de mundo particulares são defendidas. Cumpre ao leitor, assim, permanecer atento ao modo como os textos são construídos.

\section{REFERÊNCIAS}

DUQUE, Paulo Henrique. Discurso e cognição: uma abordagem baseada em frames. Anpoll, v. 1, n. 39, p. 25-48, 2015.

DUQUE, Paulo Henrique. De perceptos a frames: cognição ecológica e linguagem. Scripta, v. 21, n. 41, p. 21-45, 2017. 
FILLMORE, Charles. Frame semantics. In: LINGUISTIC SOCIETY OF KOREA (Ed.). Linguistics in the morning calm. Seoul: Hanshin Publishing Company, 1982, p. 111-137.

FILLMORE, Charles J.; BAKER, Collin. A Frames Approach to Semantic Analysis. In: HEINE, Bernd; NARROG, Heiko (Eds.). The Oxford Handbook of Linguistic Analysis. Oxford: OUP, 2009, p. 313-339.

GOFFMAN, Erving. Frame analysis: an essay on the organization of experience. Boston: Northeastern University Press, 1974.

GONÇALVES, Telmo. A abordagem do enquadramento nos estudos do jornalismo. Caleidoscópio: revista de comunicação e cultura, Lisboa, Universidade Lusófona de Humanidades e Tecnologias, n. 5/6, p. 157-167, 2005.

KÖVECSES, Zoltán. Metaphor in culture: universality and variation. Cambridge: Cambridge University Press, 2005.

LAKOFF, George. Women, Fire and Dangerous Things: what categories reveal about the mind. Chicago: University of Chicago Press, 1987.

LAKOFF, George. The Contemporary Theory of Metaphor. In: ORTONY, Andrew (Ed.). Metaphor and Thought. 2. ed. Cambridge: Cambridge University Press, 1992.

LAKOFF, George; JOHNSON, Mark. Metaphors we live by. Chicago: University of Chicago Press, 1980.

SCHRÖDER, Ulrich. A construção metafórica do conceito 'Sociedade' em perspectiva comparativa. Pandaemonium germanicum, n. 14, p. 105-141, 2009.

SOUSA, Ada Lima Ferreira de; COSTA, Marcos Antonio. Figuratividade: o complexo elo entre as palavras e as coisas. Signo, Santa Cruz do Sul, v. 41, n. 70, p. 04-14, jan./jun. 2016.

VAN DIJK, Teun Adrianus. Cognição, discurso e interação. São Paulo: Contexto, 2004.

VEREZA, Solange. "Metáfora é que nem...": cognição e discurso na metáfora situada. Signo, Santa Cruz do Sul, v. 38, n. 65, p. 2-21, jul. dez. 2013.

VEREZA, Solange. Cognição e sociedade: um olhar sob a óptica da linguística cognitiva. Linguagem em (Dis)curso, Tubarão, Santa Catarina, v. 16, n. 3, p. 561-573, set./dez. 2016.

Submetido em 23/03/2020 Aceito em 14/08/2020 